\title{
A novel N staging system for NPC based on IMRT and RTOG guidelines for lymph node levels: Results of a prospective multicentric clinical study
}

\author{
MIN KANG ${ }^{1}$, PINGTING ZHOU ${ }^{1}$, TINGTING WEI ${ }^{1}$, TINGTING ZHAO ${ }^{1}$, JIANXIONG LONG $^{2}$, GUISHENG LI $^{3}$, \\ HAOLIN YAN ${ }^{4}$, GUOSHENG FENG ${ }^{5}$, MEILIAN LIU ${ }^{6}$, JINXIAN ZHU ${ }^{7}$ and RENSHENG WANG ${ }^{1}$ \\ ${ }^{1}$ Department of Radiation Oncology, The First Affiliated Hospital of Guangxi Medical University; ${ }^{2}$ School of \\ Public Health, Guangxi Medical University, Nanning, Guangxi 530021; ${ }^{3}$ Department of Radiation Oncology, Liuzhou \\ Worker Hospital, Liuzhou, Guangxi 545000; ${ }^{4}$ Department of Radiation Oncology, First People's Hospital of Yulin City, \\ Yulin, Guangxi 537000; ${ }^{5}$ Department of Radiation Oncology, People's Hospital of Guangxi Zhuang Autonomous Region, \\ Nanning, Guangxi 530021; ' Department of Radiation Oncology, Affiliated Hospital of Guilin Medical University, Guilin, \\ Guangxi 541000; ${ }^{7}$ Department of Radiation Oncology, Wuzhou Red Cross Hospital, Wuzhou, Guangxi 543000, P.R. China
}

Received April 7, 2016; Accepted February 27, 2018

DOI: $10.3892 / \mathrm{ol} .2018 .8676$

\begin{abstract}
The present study aimed to investigate the cervical lymph node metastasis of nasopharyngeal carcinoma (NPC) and to establish a novel $\mathrm{N}$ staging standard for NPC, based on intensity modulated radiation therapy (IMRT) via a prospective multicenter clinical trial. Between January 2006 and December 2009, a total of 492 patients with NPC without distant metastasis were included in the present study. All patients were treated with IMRT. According to Radiation Therapy Oncology Group division standards, the present study proposed a novel $\mathrm{N}$ staging system following the review of magnetic resonance images in comparison with the 7 th edition of Union for International Cancer Control/American Joint Committee on Cancer (UICC/AJCC) staging system. Retropharyngeal lymph nodes, cervical lymph node level and cervical lymph node laterality were independent prognostic factors used in multivariate analyses. According to the results of the risk variety, the present study suggested that the novel N staging system included: N0 (no lymph node metastasis), N1 [retropharyngeal or/and unilateral upper cervical (I, II, III, Va, VIIb, VIII, IX and X regions) lymph node metastasis], N2 [bilateral upper cervical (I, II, III, Va, VIIb, VIII, IX and $\mathrm{X}$ regions) lymph node metastasis] and N3 (lymph node metastasis in IVa and $\mathrm{Vb}$ regions and their lower regions). The novel $\mathrm{N}$ staging system proposed in the present study performs
\end{abstract}

Correspondence to: Professor Rensheng Wang, Department of Radiation Oncology, The First Affiliated Hospital of Guangxi Medical University, 6 Shuangyong Road, Nanning, Guangxi 530021, P.R. China

E-mail:km10192013@126.com

Key words: nasopharyngeal carcinoma, $\mathrm{N}$ staging, intensity modulated radiation therapy, magnetic resonance imaging, prognosis better in risk difference and distribution balance. Furthermore, the differences of 5-year curves of distant metastasis-free survival and overall survival had greater statistically significant differences compared with the 7th edition of the UICC/AJCC staging system. The present study suggested a novel $\mathrm{N}$ staging system for cervical lymph node metastasis of NPC, which may predict the prognosis of patients with NPC in a more objective and accurate way.

\section{Introduction}

Cervical lymph node metastasis of nasopharyngeal carcinoma (NPC) has an incidence as high as $70 \%$ (1), and is a key factor that affects the clinical staging of NPC, treatment plan and prognosis (2). The current existing international standards for NPC staging originated from the 7th edition of the Union for International Cancer Control/American Joint Committee on Cancer (UICC/AJCC) staging system that is primarily based on palpation $(3,4)$. Palpation of lymph nodes usually depends on the subjectivity of doctors, which may interfere with the accuracy of staging and the development of individualized treatment plans. In previous years, intensity modulated radiation therapy (IMRT) has become an important therapy for NPC (5-12). As a type of precision radiotherapy, IMRT requires precise anatomical locations; however, the 7th edition of the UICC/AJCC staging system has included body surface positions that are used for the determination of cervical lymph node metastasis (13). For example, in this staging system, supraclavicular fossa (SCF) is defined as a triangle area formed by the upper edge of the sternal end of the clavicle, the upper edge of the outer end of the clavicle and the neck-shoulder intersection; however, this area may include the IV region and the tail of $\mathrm{V}$ region in the international cervical lymph node partition system (14). Therefore, SCF, a position that does not have accurate positioning in cross sections in imaging, cannot satisfy the requirements by IMRT. Thus, the 7 th edition of UICC/AJCC staging system 
has certain limitations regarding the outline of NPC target areas, the definition of treatment plans and the evaluation of prognosis (15).

Initially, the Radiation Therapy Oncology Group (RTOG) divides cervical lymph nodes into retropharyngeal region, I (Ia, Ib) region, II (IIa, IIb) region, III region, IV region, V region and VI region (16). Subsequently, retrostyloid space and supraclavicular region are included in a modified version of RTOG division standards (17). In 2013, RTOG division standards further defined IVb, Vc, VII, VIII, IX and X regions (18). The internationally recognized cervical lymph node imaging division standards are widely used among the radiation oncology research community. The present study used RTOG division standards and magnetic resonance imaging (MRI) to investigate cervical lymph node metastasis of NPC and to establish a novel N staging standard for NPC based on IMRT via a prospective multicenter clinical trial.

\section{Materials and methods}

Patients. Between January 2006 and December 2009 , 492 patients with NPC without distant metastasis from six hospitals (The First Affiliated Hospital of Guangxi Medical University, Nanning; Liuzhou Worker Hospital, Liuzhou; First People's Hospital of Yulin City, Yulin; People's Hospital of Guangxi Zhuang Autonomous Region, Nanning; Affiliated Hospital of Guilin Medical University, Guilin; Wuzhou Red Cross Hospital, Wuzhou, Guangxi, China) were included in the present study. Among them, 338 were male and 154 were female. The median age of the group was 45 years old (range, 18-81 years old). All patients received IMRT. Patients with a Karnofsky performance status of $\geq 70$, who met criteria for blood counts and other tests (i.e., serum creatinine $\leq 1.6 \mathrm{mg} / \mathrm{dl}$ and serum bilirubin $\leq 1.5 \mathrm{mg} / \mathrm{dl}$; white blood cell $\geq 3,600 / \mathrm{mm}^{3}$, platelet $\geq 100,000 / \mathrm{mm}^{3}$ and hemoglobin $\geq 12.0 \mathrm{~g} / \mathrm{dl}$ for males, $\geq 11.0 \mathrm{~g} / \mathrm{dl}$ for females) were eligible. Prior to treatment, all patients received detailed physical examination, general situation appraisal, blood routine examination, nasopharyngeal fiberscope examination, chest X-ray or computed tomography (CT), abdominal ultrasound and MRI of areas including the nasopharynx and neck. Patients with N2-N3 stage received additional bone scanning. All procedures were approved by the Ethics Committee of Guangxi Medical University (Nanning, China). Written informed consent was obtained from all patients or their families prior to enrolment in the present study.

MRI. MR images were obtained using a 1.5-T MRI scanner (GE Healthcare Life Sciences, Little Chalfont, UK). All patients received routing and enhanced scanning. Scanning directions were cross sectional, sagittal, coronal, T2-weighted (TR 3,000-4,000 ms, TE 102-110 ms), T1-weighted (TR 2,200-2,400 ms, TE 77-109 ms, TI $750 \mathrm{~ms}$ ) and enhanced T1-weighted scanning. Head quadrature coil was adopted, with a thickness of $6 \mathrm{~mm}$, interlayer space of $1 \mathrm{~mm}$ and matrix of 256x192. Cross-sectional scanning ranged from suprasellar cistern to the lower edge of the clavicle. The contrast medium was gadopentetate dimeglumine-diethylenetriaminepentacetate, with a dose of $15 \mathrm{ml}$.
Clinical staging. All MR images were independently reviewed using a picture archiving and communication system by two physicians. The stage of this research group was defined according to the 7th edition of UICC/AJCC clinical staging standard, taking into account patient symptoms and physical examination information. Lymph node metastasis was diagnosed by MRI, but not by palpation, according to the guidelines of RTOG 2013 edition $(19,20)$.

Therapeutic method. A total of 492 patients with NPC received IMRT during the whole process. Computed tomography contrast-enhanced scanning was applied from the skull cap to $3 \mathrm{~cm}$ below the clavicle, with a layer distance of $3 \mathrm{~mm}$ and layer thickness of $3 \mathrm{~mm}$. Under the guidance of Report 50 and Report 62 of International Commission on Radiation Units and Measurements, gross tumor volume (GTV) included primary tumor sites, and their invasion range (GTVnx), retropharyngeal metastatic lymph nodes (GTVrpn) and cervical metastatic lymph node (GTVnd) (21). The clinical target volume (CTV) range may be adjusted according to involvement degrees. For example, CTV1 should include GTVnx, GTVrpn, the whole nasopharyngeal mucosa and submucosal $5 \mathrm{~mm}$ region; CTV2 should include CTV1, as well as some of the following: Posterior nasal cavity, pterygopalatine fossa, posterior maxillary sinus, part of the posterior ethmoid sinus, lateral pharyngeal space, skull base, part of cervical vertebra and slope. Planning target volume (PTV) included position errors and organ movements during treatments, which are usually externally expanded for 3-5 mm based on GTVs and CTVs. The prescription doses were as follows: PGTVnx and PTVrpn (68-74 Gy), PTVnd (66-70 Gy), PTV1 (60-66 Gy) and PTV2 (50-56 Gy; 5 fractions/week for a total of 30-33 fractions). The setting of restricted dosages for critical organs followed international consensus $(21,22)$.

All stages were defined according to the 7 th edition of the UICC/AJCC staging standards. Of the 477 patients with Stage II-IVB disease, $93.70 \%$ patients (461/492) received chemotherapy, including 51.0\% (235/461) with concurrent chemotherapy, $37.09 \%$ (171/461) with induction + concurrent chemotherapy, $7.59 \%$ (35/461) with concurrent + adjuvant chemotherapy, $4.12 \%$ (19/461) with induction + concurrent + adjuvant chemotherapy, and $0.22 \%$ (1/461) with induction chemotherapy. The chemotherapy drugs were primarily platinum-based. All centers used identical chemotherapy protocols.

Follow-ups. Regular follow-ups commenced from 3 months after the patients ended their treatment. The follow-up period was defined as the period starting from the commencement date of treatment to the last date of regular follow-up or to the time of mortality of patients. By December 31st 2014, the last date of regular follow-up, the median follow-up period was 64.1 months (6-92 months). A percentage of $96.3 \%$ of patients had complete follow-up data of 5 years. The main analysis factors included overall survival (OS), disease-free survival (DFS), relapse-free survival (RFS) and distant metastasis-free survival (DMFS).

Statistical analysis. All results were analyzed using SPSS v19.0 statistical software (IBM Corp., Armonk, NY, USA). The 
Kaplan-Meier method was used to calculate various survival rates. The log-rank test was used to examine the significance of differences in survival rate. Analyses of prognosis were performed using univariate analysis or multivariate analysis. $\mathrm{P}<0.05$ was considered to indicate a statistically significant difference. Data are presented as the mean \pm standard error of the mean.

\section{Results}

Rate of lymph node metastasis of NPC is high, with retropharyngeal and II regional lymph nodes being the most likely to have metastasis. To determine the distribution of metastatic lymph nodes, the locations of the metastasis were recorded for all 492 patients with NPC. Among the 492 patients, 428 (87\%) had cervical lymph node metastasis, including $82(19.2 \%)$ cases with left cervical metastasis only, $77(18.0 \%)$ cases with right cervical metastasis only and $269(62.9 \%)$ cases with cervical metastasis on both sides. The number of patients with retropharyngeal lymph node metastasis was 339 (79.2\%), including 128 cases of bilateral metastasis $(38.1 \%)$ and 210 cases of unilateral metastasis (61.9\%). The number of patients with II regional lymph node metastasis was $351(82.0 \%)$, including 189 cases of bilateral metastasis (44.2\%; Table I). Among the 428 patients with lymph node metastasis, only 4 patients without II regional metastasis had III regional metastasis $(0.9 \%)$, including 1 case that demonstrated $\mathrm{IV}, \mathrm{Va}$ and $\mathrm{Vb}$ regional metastasis. Among patients without II and III regional metastasis, no IV regional metastasis was observed. These results suggested that the rate of lymph node metastasis of NPC was high, with retropharyngeal and II regional lymph nodes being the most likely to have metastasis.

Retropharyngeal lymph nodes, cervical lymph node level and cervical lymph node laterality are associated with the prognosis of patients. To investigate the association between lymph node characteristics and prognosis, univariate analysis and multivariate analysis were performed. According to the 7th edition of the UICC/AJCC staging system, patients at I, II, III, IVa, and IVb stages accounted for 3.0\% (15/492), 14.4\% (71/492), 35.8\% (176/492), 38.0\% (187/492) and 8.7\% (43/492), respectively. In addition, patients at $\mathrm{T} 1, \mathrm{~T} 2, \mathrm{~T} 3$ and $\mathrm{T} 4$ stages accounted for $6.7 \%$ (33/492), 18.5\% (91/492), 33.7\% (166/492) and $41.1 \%$ (202/492), respectively. Furthermore, patients at NO, N1, N2, N3a and N3b stages accounted for $13.0 \%$ (64/492), $32.3 \%$ (159/492), $45.9 \%$ (226/492), $2.2 \%$ (11/492) and 6.5\% (32/492), respectively (data not shown). The OS rate after 5 years was $80.5 \%$, the DFS rate was $78.6 \%$, the RFS rate was $94.1 \%$ and the DMFS rate was $84.3 \%$. Univariate analysis of 428 patients with cervical lymph node metastasis demonstrated that lymph nodal level, sizes [measured as the maximum diameter $\left.\left(D_{\max }\right)\right]$ had a statistically significant effect on OS, DFS and DMFS, cervical lymph node laterality and retropharyngeal region had a statistically significant effect on OS, DFS, RFS and DMFS, and extracapsular spread had a statistically significant effect on OS, whereas liquefaction necrosis had no significant effect (Table II). In addition, distant metastasis survival and overall survival in Ib, retropharyngeal (VIIa), III and Va regions were not significantly different from II region,
Table I. Percentage and distribution of the metastatic lymph nodes in 428 patients with NPC.

\begin{tabular}{lcccc}
\hline & \multicolumn{4}{c}{ No. of patients $(\%)$} \\
\cline { 2 - 5 } Level & Left & Right & Bilateral & Total \\
\hline Ia & $0(0.0)$ & $0(0.0)$ & $0(0.0)$ & $0(0.0)$ \\
Ib & $3(0.7)$ & $6(1.4)$ & $1(0.2)$ & $8(1.9)$ \\
II & $254(59.3)$ & $286(66.8)$ & $189(44.2)$ & $351(82.0)$ \\
III & $104(24.3)$ & $99(23.1)$ & $35(8.2)$ & $168(47.4)$ \\
IVa & $21(4.9)$ & $15(3.5)$ & $4(0.9)$ & $32(7.5)$ \\
IVb & $1(0.2)$ & $0(0.0)$ & $0(0.0)$ & $1(0.2)$ \\
Va & $10(2.3)$ & $8(1.9)$ & $1(0.2)$ & $17(4.0)$ \\
Vb & $4(0.9)$ & $5(1.2)$ & $0(0.0)$ & $9(2.1)$ \\
Vc & $1(0.2)$ & $1(0.2)$ & $0(0.0)$ & $2(0.5)$ \\
VI & $0(0.0)$ & $0(0.0)$ & $0(0.0)$ & $0(0.0)$ \\
VIIa & $239(55.8)$ & $228(53.3)$ & $129(38.1)$ & $339(79.2)$ \\
VIIb & $0(0.0)$ & $0(0.0)$ & $0(0.0)$ & $0(0.0)$ \\
VIII & $0(0.0)$ & $0(0.0)$ & $0(0.0)$ & $0(0.0)$ \\
IX & $0(0.0)$ & $0(0.0)$ & $0(0.0)$ & $0(0.0)$ \\
Xa & $0(0.0)$ & $0(0.0)$ & $0(0.0)$ & $0(0.0)$ \\
Xb & $0(0.0)$ & $0(0.0)$ & $0(0.0)$ & $0(0.0)$ \\
\hline
\end{tabular}

NPC, nasopharyngeal carcinoma.

whereas those in IVa, $\mathrm{Vb}$ and lower regions were significantly different from the II region. Therefore, lymph node levels were divided into two groups: Level 1 (L1), retropharyngeal (VIIa), Ib, II, III and Va regions; and level 2 (L2), IVa, IVb, Vb and $\mathrm{Vc}$ regions (Table III). Multivariate analysis of all 492 patients revealed that $D_{\max }$ of cervical lymph nodes, extracapsular spread and liquefaction necrosis did not have independent prognostic significance. Of note, retropharyngeal lymph nodes, cervical lymph node level and cervical lymph node laterality were independent prognostic factors (Table IV). These results indicated that retropharyngeal lymph nodes, cervical lymph node level and cervical lymph node laterality are associated with the prognosis of patients.

Novel $N$ staging system proposed in the present study is more suitable for IMRT compared with the 7th edition of the UICC/AJCC staging system. According to univariate and multivariate analysis results, the 492 patients included in the present study were classified into six subgroups, including the N0 group (no lymph node metastasis), retropharyngeal lymph nodes (Nrp) group, L1Lu group (unilateral upper cervical lymph node metastasis), L1Lb group (bilateral upper cervical lymph node metastasis), L2Lu group (unilateral lower cervical lymph node metastasis) and L2Lb group (bilateral lower cervical lymph node metastasis). Compared with the L1Lu group (hazard ratio=1), the hazard ratio for the risk of distant metastasis survival and overall survival in the N0 group was 0 . Thus, N0 group was classified as N0 stage. Compared with the L1Lu group (hazard ratio=1), the hazard ratio for the risk of distant metastasis survival in the Nrp group was 1.367 and the risk of overall survival was 1.857 . Statistically, the L1Lu and 
Table II. Univariate analysis of the association between various cervical lymph node variables and patient prognosis.

\begin{tabular}{|c|c|c|c|c|c|c|c|c|c|c|c|c|}
\hline Variables & OS & $\chi^{2}$ & P-value & DFS & $\chi^{2}$ & P-value & RFS & $\chi^{2}$ & P-value & DMFS & $\chi^{2}$ & P-value \\
\hline Level & & 30.003 & $<0.001$ & & 22.774 & 0.001 & & 1.170 & 0.978 & & 31.184 & $<0.001$ \\
\hline Level IB & - & & & - & & & - & & & - & & \\
\hline Level II & 82.7 & & & 81.9 & & & 94.4 & & & 87.7 & & \\
\hline Level III & 75.2 & & & 73.6 & & & 93.3 & & & 79.9 & & \\
\hline Level IVa & 67.0 & & & 65.6 & & & 93.3 & & & 71.9 & & \\
\hline Level Va & 92.3 & & & 65.9 & & & 91.7 & & & 74.0 & & \\
\hline Level $\mathrm{Vb}$ & 37.0 & & & 44.4 & & & 100 & & & 44.4 & & \\
\hline Level $(\mathrm{IVb}+\mathrm{Vc})$ & 33.3 & & & 33.3 & & & 100 & & & 33.3 & & \\
\hline Level VIIa & 78.9 & & & 86.5 & & & 91.7 & & & 85.9 & & \\
\hline Group & & 12.109 & 0.001 & & 10.682 & 0.001 & & 0.062 & 0.803 & & 13.792 & $<0.001$ \\
\hline Level 1 & 79.8 & & & 78.0 & & & 93.6 & & & 83.9 & & \\
\hline Level 2 & 39.2 & & & 59.1 & & & 95.0 & & & 63.6 & & \\
\hline $\mathrm{D}_{\max }, \mathrm{cm}$ & & 14.566 & 0.001 & & 15.728 & $<0.001$ & & 0.575 & 0.750 & & 14.068 & 0.001 \\
\hline$\leq 3$ & 81.0 & & & 77.3 & & & 93.6 & & & 83.3 & & \\
\hline$>3$ and $\geq 6$ & 78.1 & & & 76.4 & & & 94.8 & & & 81.3 & & \\
\hline$>6$ & 45.5 & & & 36.4 & & & 90.9 & & & 45.5 & & \\
\hline Laterality & & 12.640 & $<0.001$ & & 11.866 & 0.001 & & 4.645 & 0.031 & & 6.682 & 0.010 \\
\hline Unilateral & 89.2 & & & 86.3 & & & 97.6 & & & 88.5 & & \\
\hline Bilateral & 71.2 & & & 70.3 & & & 92.0 & & & 77.7 & & \\
\hline RLN & & 17.872 & 0.046 & & 14.199 & $<0.001$ & & 4.710 & 0.030 & & 8.970 & 0.003 \\
\hline No & 96.2 & & & 91.9 & & & 98.9 & & & 93.0 & & \\
\hline Yes & 73.3 & & & 71.9 & & & 92.3 & & & 78.9 & & \\
\hline Extracapsular spread & & 6.071 & 0.014 & & 1.700 & 0.192 & & 0.001 & 0.976 & & 1.921 & 0.166 \\
\hline No & 86.0 & & & 79.4 & & & 93.7 & & & 85.4 & & \\
\hline Yes & 73.8 & & & 74.5 & & & 93.9 & & & 80.2 & & \\
\hline Necrosis & & 0.426 & 0.514 & & 1.754 & 0.185 & & 2.636 & 0.104 & & 0.315 & 0.574 \\
\hline No & 78.2 & & & 77.2 & & & 94.7 & & & 82.2 & & \\
\hline Yes & 72.7 & & & 70.2 & & & 89.0 & & & 80.2 & & \\
\hline
\end{tabular}

OS, overall survival; DFS, disease-free survival; RFS, relapse-free survival; DMFS, distant metastasis-free survival; $\mathrm{D}_{\max }$, maximum diameter; RLN, retropharyngeal lymph nodes.

Nrp groups had no significant difference. Thus, the L1Lu and Nrp group were classified as N1 stage. However, the hazard ratio for the risk of distant metastasis survival and overall survival in the L1Lb group was 2.142 and 2.755, respectively, significantly compared with that in the L1Lu group $(\mathrm{P}<0.05)$. Thus, the L1Lb group was classified as N2 stage. Compared with the L1Lu group, the hazard ratio for the risk of distant metastasis survival and overall survival in the L2Lu group (3.825 and 3.835, respectively), and in the L2Lb group (4.785 and 5.415, respectively) was also significantly higher $(\mathrm{P}<0.05)$. Thus, the L2Lu and L2Lb groups were classified as N3 stage (Table V). According to the effects of different factors on prognosis, the present study proposed novel N staging standards: N0 (no lymph node metastasis), N1 [retropharyngeal or/and unilateral upper cervical (I, II, III, Va, VIIb, VIII, IX and X regions) lymph node metastasis], N2 [bilateral upper cervical (I, II, III, Va, VIIb, VIII, IX and X regions) lymph node metastasis] and $\mathrm{N} 3$ (lymph node metastasis in IVa and Vb regions and their lower regions). To evaluate the novel $\mathrm{N}$ staging, differences in the survival prediction value, the distribution balance and the risk ratio were compared between the novel $\mathrm{N}$ staging and the 7th edition of the UICC/AJCC staging system. In the proposed novel $\mathrm{N}$ staging system, the OS curves were significantly different among all stages: N0:N1 $\left(\chi^{2}=5.198, \mathrm{P}<0.05\right)$, N0:N2 $\left(\chi^{2}=14.663, \mathrm{P}<0.01\right), \mathrm{N} 0: \mathrm{N} 3\left(\chi^{2}=29.990, \mathrm{P}<0.01\right), \mathrm{N} 1: \mathrm{N} 2$ $\left(\chi^{2}=9.215, \mathrm{P}<0.01\right), \mathrm{N} 1: \mathrm{N} 3\left(\chi^{2}=22.592, \mathrm{P}<0.01\right)$ and $\mathrm{N} 2: \mathrm{N} 3$ $\left(\chi^{2}=9.305, \mathrm{P}<0.01\right)$. In addition, the DMFS curves were significantly different among all stages: N0:N1 $\left(\chi^{2}=5.528, \mathrm{P}<0.05\right)$, N0:N2 $\left(\chi^{2}=11.748, \mathrm{P}<0.01\right), \mathrm{N} 0: \mathrm{N} 3\left(\chi^{2}=25.172, \mathrm{P}<0.01\right), \mathrm{N} 1: \mathrm{N} 2$ $\left(\chi^{2}=8.525, \mathrm{P}<0.01\right), \mathrm{N} 1: \mathrm{N} 3\left(\chi^{2}=18.934, \mathrm{P}<0.01\right)$ and $\mathrm{N} 2: \mathrm{N} 3$ $\left(\chi^{2}=7.315, \mathrm{P}<0.01\right.$; Fig. 1, Table VI). Conversely, OS and DMFS curves were not significantly different between N3a and N3b stages according to the 7th edition of the UICC/AJCC staging system (Fig. 1, Table VI). Furthermore, the ratio of distribution in N3a and N3b stages in the 7th edition of the UICC/AJCC staging system accounted for 2.2 and $6.5 \%$, respectively, whereas the $\mathrm{N} 3$ stage in the proposed novel $\mathrm{N}$ staging system accounted for $8.9 \%$, being more balanced compared with the 
Table III. Comparison of distant metastasis survival and OS of various lymph node levels.

Risk ratio $(95 \% \mathrm{CI})$

\begin{tabular}{lrcc} 
Nodal variables & No. & Distant metastasis survival & OS \\
\hline Level II & 196 & 1 & 1 \\
Level VIIa & 37 & $0.998(0.382-2.607)$ & $1.080(0.475-2.452)$ \\
Level III & 138 & $1.565(0.909-2.697)$ & $1.520(0.934-2.474)$ \\
Level IVa & 32 & $2.357(1.100-5.050)^{\mathrm{a}}$ & $2.124(1.041-4.335)^{\mathrm{a}}$ \\
Level Va & 13 & $1.779(0.537-5.893)$ & $0.462(0.063-3.381)$ \\
Level Vb & 9 & $6.318(2.415-16.532)^{\mathrm{a}}$ & $5.302(2.057-13.667)^{\mathrm{a}}$ \\
Level $(\mathrm{IVb}+\mathrm{Vc})$ & 3 & $10.559(2.492-44.750)^{\mathrm{a}}$ & $10.491(2.483-44.318)^{\mathrm{a}}$ \\
Level Ib & 0 & - & - \\
\hline
\end{tabular}

${ }^{\mathrm{a}} \mathrm{P}<0.05$. OS, overall survival; $\mathrm{CI}$, confidence interval.

Table IV. Multivariate analysis of cervical lymph node variables associated with prognosis.

\begin{tabular}{|c|c|c|c|c|}
\hline Variables & OS & DFS & RFS & DMFS \\
\hline Levels 1 and 2 & 0.007 & 0.003 & 0.006 & 0.003 \\
\hline $\mathrm{D}_{\max }$ & 0.918 & 0.764 & 0.793 & 0.945 \\
\hline Laterality & 0.006 & 0.006 & 0.004 & 0.007 \\
\hline RLN & $<0.001$ & $<0.001$ & $<0.001$ & 0.001 \\
\hline Extracapsular spread & 0.909 & 0.999 & 0.962 & 0.925 \\
\hline Necrosis & 0.242 & 0.424 & 0.232 & 0.193 \\
\hline
\end{tabular}

OS, overall survival; DFS, disease-free survival; RFS, relapse-free survival; DMFS, distant metastasis-free survival; $\mathrm{D}_{\max }$, maximum diameter; RLN, retropharyngeal lymph nodes.

Table V. Distribution patterns and failure hazards of different $\mathrm{N}$ subsets.

\begin{tabular}{lcc}
\hline & \multicolumn{2}{c}{ Hazard ratio $(95 \%$ CI $)$} \\
\cline { 2 - 3 } Group & Distant metastasis survival & OS \\
\hline L1Lu & 1 & 1 \\
N0 & $0.152(0.020-1.166)$ & $0.271(0.061-1.201)$ \\
Nrp & $1.367(0.481-3.879)$ & $1.857(0.071-4.657)$ \\
L1Lb & $2.142(1.129-4.064)^{\mathrm{b}}$ & $2.755(1.499-5.065)^{\mathrm{a}}$ \\
L2Lu & $3.825(1.079-13.556)^{\mathrm{b}}$ & $3.835(1.092-13.471)^{\mathrm{a}}$ \\
L2Lb & $4.785(2.181-10.497)^{\mathrm{b}}$ & $5.415(2.537-11.562)^{\mathrm{a}}$ \\
\hline
\end{tabular}

${ }^{\mathrm{a}} \mathrm{P}<0.05$. OS, overall survival; CI, confidence interval.

7th edition of the UICC/AJCC staging system (Table VII). In addition, the risk ratio for each stage in the proposed novel $\mathrm{N}$ staging system was significantly different compared with the N0 stage $(\mathrm{P}<0.05)$, whereas the risk ratio for the N1 stage in the 7th edition of the UICC/AJCC staging system was not significantly different compared with the N0 stage $(\mathrm{P}>0.05$; Table VII). These results suggested that the novel N staging system proposed in the present study was more suitable for
IMRT compared with the 7th edition of the UICC/AJCC staging system.

\section{Discussion}

NPC has a high rate of cervical lymph node metastasis and $\sim 70 \%$ of patients were diagnosed with cervical lymph node metastasis at their preliminary diagnosis $(1,23)$. The MRI data in the present study demonstrated that $87.0 \%$ of 492 patients had lymph node metastasis, which was consistent with the results reported by Wang et al (24) and Ho et al (25). The metastatic rates for retropharyngeal, II, III, IV, Va, Vb and $\mathrm{Vc}$ regions were 79.2, 82.0, 47.4, 7.7, 4.0, 2.1 and $0.5 \%$, respectively. Consistent with a previous study, the metastatic rates of each region decreased from the upper region to the lower region, and the skipping metastatic rate was $0.9 \%$ (26). However, it has not been confirmed whether the retropharyngeal or II region lymph node is the sentinel lymph node (1,27-30). Lv et al (31) revealed that the metastatic rates of retropharyngeal and II region lymph nodes were 74.5 and $75.3 \%$, respectively, suggesting that both are sentinel lymph nodes. Consistent with this observation, the present study demonstrated that the metastatic rates of retropharyngeal and II region lymph nodes in 428 patients were 351 cases $(82.0 \%)$ and 339 cases $(79.2 \%)$, respectively. This observation may be associated with lymph node drainage via retropharyngeal 
Table VI. OS rate and distant failure-free rates of various $\mathrm{N}$ stages between the proposed system and the 7 th edition of the UICC/AJCC system.

\begin{tabular}{|c|c|c|c|c|}
\hline & \multicolumn{2}{|c|}{ OS } & \multicolumn{2}{|c|}{ DMFS } \\
\hline & $\mathrm{X} 2$ & $\mathrm{P}$ & $\mathrm{X} 2$ & $\mathrm{P}$ \\
\hline \multicolumn{5}{|c|}{ Proposed system } \\
\hline N0:N1 & 5.198 & 0.039 & 5.528 & 0.042 \\
\hline N0:N2 & 14.663 & $<0.001$ & 11.748 & $<0.001$ \\
\hline N0:N3 & 29.990 & $<0.001$ & 25.172 & $<0.001$ \\
\hline $\mathrm{N} 1: \mathrm{N} 2$ & 9.215 & 0.001 & 8.525 & 0.002 \\
\hline N1:N3 & 22.592 & $<0.001$ & 18.934 & $<0.001$ \\
\hline $\mathrm{N} 2: \mathrm{N} 3$ & 9.305 & $<0.001$ & 7.315 & $<0.001$ \\
\hline \multicolumn{5}{|c|}{ UICC/AJCC system } \\
\hline N0:N1 & 4.203 & 0.040 & 4.325 & 0.038 \\
\hline N0:N2 & 14.104 & $<0.001$ & 11.197 & 0.001 \\
\hline N0:N3a & 39.270 & $<0.001$ & 39.328 & $<0.001$ \\
\hline $\mathrm{N} 0: \mathrm{N} 3 \mathrm{~b}$ & 34.506 & $<0.001$ & 31.973 & $<0.001$ \\
\hline N1:N2 & 11.438 & 0.001 & 6.491 & 0.011 \\
\hline N1:N3a & 35.277 & $<0.001$ & 28.276 & $<0.001$ \\
\hline $\mathrm{N} 1: \mathrm{N} 3 \mathrm{~b}$ & 34.218 & $<0.001$ & 31.427 & $<0.001$ \\
\hline $\mathrm{N} 2: \mathrm{N} 3 \mathrm{a}$ & 6.544 & 0.011 & 9.797 & 0.002 \\
\hline $\mathrm{N} 2: \mathrm{N} 3 \mathrm{~b}$ & 9.510 & 0.002 & 12.721 & $<0.001$ \\
\hline N3a:N3b & 0.121 & 0.728 & 0.070 & 0.792 \\
\hline
\end{tabular}

OS, overall survival; DMFS, distant metastasis-free survival; UICC/AJCC, Union for International Cancer Control/American Joint Committee on Cancer.

and II regions. In the 7th edition of the UICC/AJCC staging system, retropharyngeal lymph node metastasis was classified as N1 (32). Tang et al (33) recommended classifying retropharyngeal lymph node metastasis as N1. The results of the present study revealed that retropharyngeal lymph node metastasis (regardless of sides and sizes) is an independent prognostic factor that affects OS, DFS, RFS and DMFS of patients with NPC. Due to various N staging standards of NPC that have distinct lymph node parameters $(15,20,29,34,35)$, the present study suggested setting a unified standard based on objective MRI data and international lymph node imaging division method.

Supraclavicular fossa defined in the 7 th edition of the UICC/AJCC staging system has been demonstrated to have high risk of distant metastasis. According to the RTOG for Lymph Node criteria, supraclavicular fossa is located at IV region, the lower part of $\mathrm{V}$ region and the whole supraclavicular region (13). Cervical lymph nodes are an ordered defense system. Once supraclavicular lymph nodes are affected, tumor cells may further invade thoracic ducts and possibly the whole body. Mao et al (34) suggested that lymph node metastasis regions may be categorized into retropharyngeal, Ib, II, III, V and IV regions, as well as the supraclavicular region, when using the $\mathrm{N}$ staging based on MRI and RTOG to evaluate distant metastasis risks. Ng et al (15) and Yue et al (36) suggested replacing supraclavicular fossae in
UICC/AJCC standards with IV and $\mathrm{Vb}$ regions. Li et al (37) revealed that lower cervical lymph node metastasis (IV, Vb and supraclavicular regions) is an independent prognostic factor that affects survival (37). Consistent with these reports, the present study divided the lymph node level into Level 1 (retropharyngeal, Ib, II, III and Va regions) and Level 2 (IVa, IVb, Vb and Vc regions), and univariate and multivariate analyses confirmed the significant differences in prognosis between the two.

NPC usually metastasizes according to the direction of lymphatic drainage (38). As it is different from other malignant tumors in the head and neck, NPC usually has lymph node metastasis (bilateral or unilateral) during its early stage, with a $40 \%$ rate of bilateral lymph node metastasis (39). The primary difference between $\mathrm{N} 1$ and $\mathrm{N} 2$ stages in the 7th edition of the UICC/AJCC staging system is unilateral or bilateral lymph node metastasis. The present study demonstrated that OS, DFS, RFS and DMFS rates were significantly different between unilateral and bilateral metastases, suggesting that cervical lymph node laterality is an independent prognostic factor for NPC.

A previous literature review investigating the data for the N-staging system for NPC revealed that the prognostic significance attributed to size was controversial (40-44). Lee et al (4) demonstrated that the largest lymph node size was independently significant in predicting survival. However, certain reports revealed that lymph node size was not an independent prognostic factor (40-43). The multivariate analysis of present study indicated that lymph node size was not an independent prognostic factor. According to the 7 th edition of the UICC/AJCC staging system, the diagnosis of lymph nodes $>6 \mathrm{~cm}$ was primarily based on palpation, which is subjective. Few lymph nodes $>6 \mathrm{~cm}$ may be diagnosed by MRI or CT. Therefore, it is still controversial whether lymph node size should be included in the $\mathrm{N}$ staging standards.

The prognostic significance of extracapsular spread in the treatment of NPC remains unclear. Mao et al (34) suggested that lymph node extracapsular spread should be classified into N2 stage as a staging factor. The results of the univariate analysis of the present study demonstrated that extracapsular spread does not significantly affect RFS, DMFS and DFS rates. In addition, multivariate analysis indicated that cervical lymph node extracapsular spread was not an independent prognostic factor. This may be due to the lack of pathological evidence and diagnostic standard. Therefore, extracapsular spread is not included in the proposed novel $\mathrm{N}$ staging system.

The tumor-node-metastasis staging system is the comprehensive manifestation of all types of prognosis factors revealed by the investigation of clinical epidemiology, and the identification of novel prognostic factors depends on the improvement of diagnosis and therapy. Due to the continuous improvement of diagnosis and therapy, prognostic factors are also changing, and staging system should also be continuously improved. The staging standard of the 7th edition of the UICC/AJCC published in 2009 is primarily based on the data of regular two-dimensional radiotherapy. As the progress of accurate radiotherapy, IMRT has been more frequently applied in the treatment of NPC than regular two-dimensional radiotherapy (44-46). In addition, the 
Table VII. Distribution and differences in risk ratios between the 7th edition of the UICC/AJCC staging system and the proposed novel $\mathrm{N}$ staging system.

Risk ratio $(95 \% \mathrm{CI})$

N stage $\quad$ No. $\quad$ Distant metastasis survival OS

Proposed system

$\begin{array}{lc}\text { N0 } & 64(13.0) \\ \text { N1 } & 161(32.7) \\ \text { N2 } & 223(45.3) \\ \text { N3 } & 44(8.9)\end{array}$

UICC/AJCC system

$\begin{array}{lc}\text { N0 } & 64(13.0) \\ \text { N1 } & 159(32.3) \\ \text { N2 } & 226(45.9) \\ \text { N3a } & 11(2.2) \\ \text { N3b } & 32(6.5)\end{array}$

1

$7.557(1.009-56.613)^{\mathrm{a}}$

$13.827(1.903-100.486)^{\mathrm{a}}$

$30.123(3.993-227.251)^{\mathrm{a}}$

1

$6.316(0.834-47.812)$

$13.288(1.827-96.612)^{\mathrm{a}}$

$51.936(6.243-432.084)^{\mathrm{a}}$

$38.744(5.091-294.830)^{\mathrm{a}}$

OS

1

$4.596(1.077-19.609)^{\mathrm{a}}$

$10.000(2.431-41.132)^{\mathrm{a}}$

$18.584(4.282-80.651)^{\mathrm{a}}$

\section{1}

$3.955(0.917-17.050)$

$9.719(2.361-40.006)^{\mathrm{a}}$

$36.384(7.268-182.153)^{\mathrm{a}}$

$23.544(5.369-103.245)^{\mathrm{a}}$

${ }^{\mathrm{a}} \mathrm{P}<0.05$ compared with N0. OS, overall survival; UICC/AJCC, Union for International Cancer Control/American Joint Committee on Cancer; CI, confidence interval.
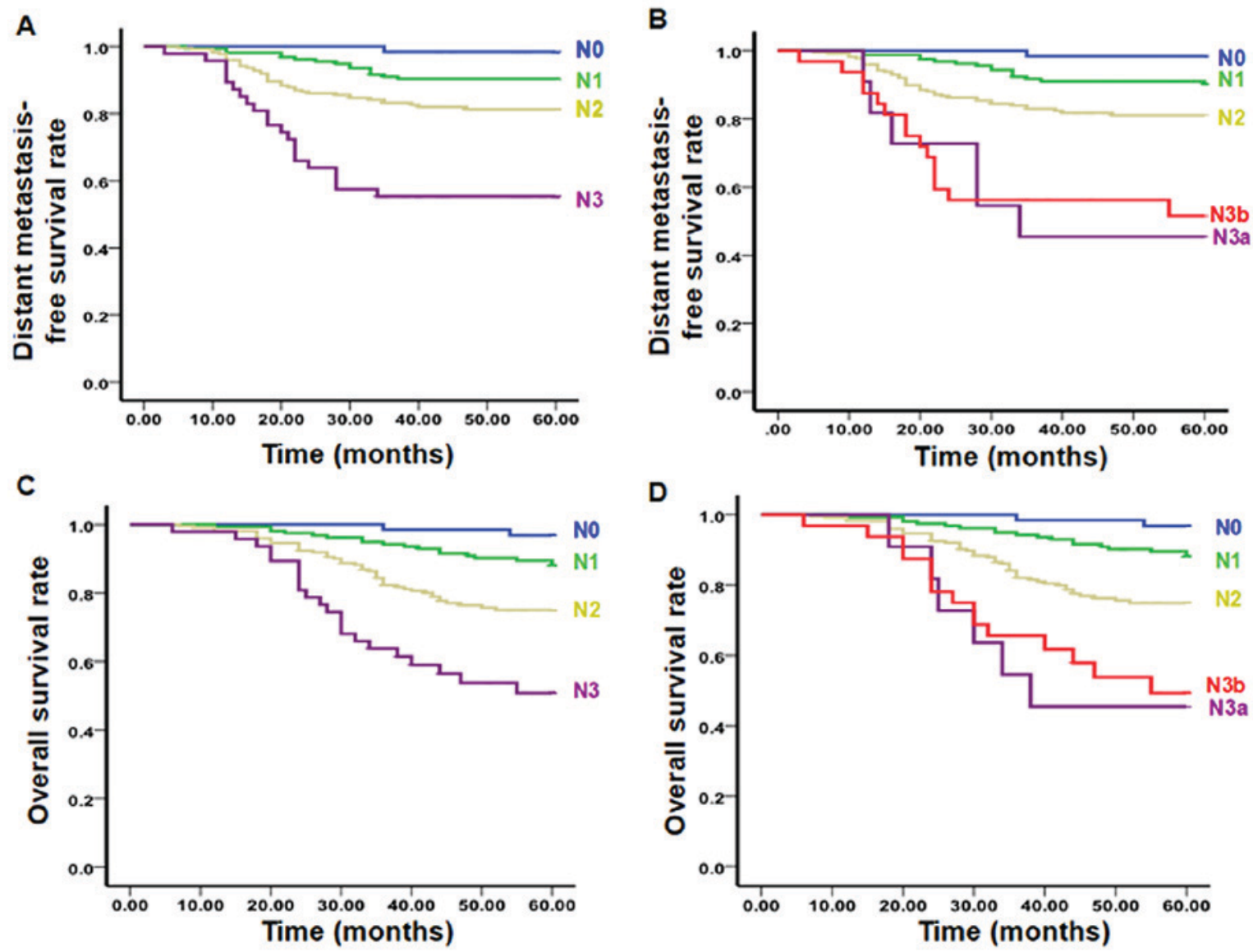

Figure 1. Distant failure-free rates of various N stages as defined by the (A) proposed system and (B) the 7th UICC/AJCC system. Overall survival rate of various N stages as defined by the (C) proposed system and the (D) 7th UICC/AJCC system. UICC/AJCC, Union for International Cancer Control/American Joint Committee on Cancer.

7th edition of UICC/AJCC is primarily based on palpation $(3,4)$. Palpation of lymph nodes usually depends on the subjectivity of doctors, which may interfere with the accuracy of staging and the development of individualized treatment plans (34). Previous 
studies have demonstrated that there were no significant differences in DMFS between N3a and N3b, and suggested that N3a and N3b may be combined as N3 in the novel N stage $(47,48)$. The present study used RTOG division standards and MRI to investigate cervical lymph node metastasis of NPC, and to establish a novel N staging standard for NPC based on IMRT in a prospective multicenter clinical trial. It was proposed that the novel N staging system include: N0 (no lymph node metastasis), N1 [retropharyngeal or/and unilateral upper cervical (I, II, III, Va, VIIb, VIII, IX and X regions) lymph node metastasis], N2 [bilateral upper cervical (I, II, III, Va, VIIb, VIII, IX and X regions) lymph node metastasis] and N3 (lymph node metastasis in IVa and $\mathrm{Vb}$ regions and their lower regions). Compared with the 7th edition of the UICC/AJCC staging system, the novel $\mathrm{N}$ staging system has improved risk difference and distribution balance, as well as distinct DMFS rate and OS rate between stages. In conclusion, the novel $\mathrm{N}$ staging system is more suitable for IMRT and more accurately predicts the prognosis of patients with NPC.

\section{Acknowledgements}

Not applicable.

\section{Funding}

The present study was supported by grants from the National Natural Science Foundation of China (grant nos. 81460460, 81360405 and 81760542), The Research Foundation of the Science and Technology Department of Guangxi Province, China (grant nos. 2016GXNSFAA380252 and 2014GXNSFBA118114), Guangxi Medical University Training Program for Distinguished Young Scholars (2017), The central government guide local science and technology development projects (ZY18057006). Medical Excellence Award Funded by the Creative Research Development Grant from the First Affiliated Hospital of Guangxi Medical University.

\section{Availability of data and materials}

All data generated or analyzed during this study are included in this published article.

\section{Authors' contributions}

MK and RW designed the research and assigned the tasks to teams. PZ, TW, TZ and JL collected and analyzed data. MK accessed the relevant information. GL and HY helped with MRI examination. ML and GF participated in image analysis. JZ was involved in statistical analysis. RW, GL, HY, GF, ML and JZ critically revised the manuscript for important intellectual content. RW approved the final version of the manuscript to be submitted.

\section{Ethics approval and consent to participate}

All procedures were approved by the Ethics Committee of Guangxi Medical University (Nanning, China). Written informed consent was obtained from all patients or their families prior to enrolment in the present study.

\section{Consent for publication}

Not applicable.

\section{Competing interests}

The authors declared that they have no competing interests.

\section{References}

1. Tang L, Mao Y, Liu L, Liang S, Chen Y, Sun Y, Liao X, Lin A, Liu M, Li L and Ma J: The volume to be irradiated during selective neck irradiation in nasopharyngeal carcinoma: Analysis of the spread patterns in lymph nodes by magnetic resonance imaging. Cancer 115: 680-688, 2009.

2. Yi J, Gao L, Huang X, Luo J, Xiao J, Li S, Wang K, Zhang S, Qu Y and Xu G: Nasopharyngeal carcinoma treated by intensity-modulated radiotherapy: Long-term results of 416 patients. Chin J Radiat Oncol 21: 196-200, 2012.

3. Edge SB and Compton CC: The American Joint Committee on Cancer: The 7th edition of the AJCC cancer staging manual and the future of TNM. Ann Surg Oncol 17: 1471-1474, 2010.

4. Lee AW, Foo W, Poon YF, Law CK, Chan DK, O SK, Tung SY and Ho JH: Staging of nasopharyngeal carcinoma: Evaluation of $\mathrm{N}$-staging by Ho and UICC/AJCC systems. Union Internationale Contre le Cancer. American Joint Committee for Cancer. Clin Oncol (R Coll Radiol) 8: 146-154, 1996.

5. Lee AW, Sze WM, Au JS, Leung SF, Leung TW, Chua DT, Zee BC, Law SC, Teo PM, Tung SY, et al: Treatment results for nasopharyngeal carcinoma in the modern era: The Hong Kong experience. Int J Radiat Oncol Biol Phys 61: 1107-1116, 2005.

6. Lee AW, Lin JC and Ng WT: Current management of nasopharyngeal cancer. Semin Radiat Oncol 22: 233-244, 2012.

7. Wong FC, Ng AW, Lee VH, Lui CM, Yuen KK, Sze WK, Leung TW and Tung SY: Whole-field simultaneous integrated-boost intensity-modulated radiotherapy for patients with nasopharyngeal carcinoma. Int J Radiat Oncol Biol Phys 76: 138-145, 2010.

8. Lee N, Harris J, Garden AS, Straube W, Glisson B, Xia P, Bosch W, Morrison WH, Quivey J, Thorstad W, et al: Intensity-modulated radiation therapy with or without chemotherapy for nasopharyngeal carcinoma: Radiation therapy oncology group phase II trial 0225. J Clin Oncol 27: 3684-3690, 2009.

9. Lee N, Xia P, Quivey JM, Sultanem K, Poon I, Akazawa C, Akazawa P, Weinberg V and Fu KK: Intensity-modulated radiotherapy in the treatment of nasopharyngeal carcinoma: An update of the UCSF experience. Int J Radiat Oncol Biol Phys 53: 12-22, 2002.

10. Lee AW, Lau WH, Tung SY, Chua DT, Chappell R, Xu L, Siu L, Sze WM, Leung TW, Sham JS, et al: Preliminary results of a randomized study on therapeutic gain by concurrent chemotherapy for regionally-advanced nasopharyngeal carcinoma: NPC-9901 trial by the Hong Kong nasopharyngeal cancer study group. J Clin Oncol 23: 6966-6975, 2005.

11. Lin S, Pan J, Han L, Zhang X, Liao X and Lu JJ: Nasopharyngeal carcinoma treated with reduced-volume intensity-modulated radiation therapy: Report on the 3-yr outcome of a prospective series. Int J Radiat Oncol Biol Phys 75: 1071-1078, 2009.

12. Kam MK, Leung SF, Zee B, Chau RM, Suen JJ, Mo F, Lai M, Ho R, Cheung KY, Yu BK, et al: Prospective randomized study of intensity-modulated radiotherapy on salivary gland function in early-stage nasopharyngeal carcinoma patients. J Clin Oncol 25: 4873-4879, 2007.

13. Edge SB, Byrd DR, Compton CC, Fritz AG, Greene FL, Trotti A, editors. AJCC cancer staging manual (7th ed). New York, NY: Springer; 2010.

14. Som PM, Curtin HD and Mancuso AA: Imaging-based nodal classification for evaluation of neck metastatic adenopathy. AJR Am J Roentgenol 174: 837-844, 2000.

15. Ng WT, Lee AW, Kan WK, Chan J, Pang ES, Yau TK and Lau KY: N-staging by magnetic resonance imaging for patients with nasopharyngeal carcinoma: Pattern of nodal involvement by radiological levels. Radiother Oncol 82: 70-75, 2007.

16. Grégoire V, Levendag P, Ang KK, Bernier J, Braaksma M, Budach V, Chao C, Coche E, Cooper JS, Cosnard G, et al: CT-based delineation of lymph node levels and related CTVs in the node-negative neck: DAHANCA, EORTC, GORTEC, NCIC, RTOG consensus guidelines. Radiother Oncol 69: 227-236, 2003.

17. Grégoire V, Eisbruch A, Hamoir M and Levendag P: Proposal for the delineation of the nodal CTV in the node-positive and the post-operative neck. Radiother Oncol 79: 15-20, 2006. 
18. Grégoire V, Ang K, Budach W, Grau C, Hamoir M,Langendijk JA, Lee A, Le QT, Maingon P, Nutting C, et al: Delineation of the neck node levels for head and neck tumors: A 2013 update. DAHANCA, EORTC, HKNPCSG, NCIC CTG, NCRI, RTOG, TROG consensus guidelines. Radiother Oncol 110: 172-181, 2014

19. Gao Y, Hu C, Ying H, Guopei Z, Ling K, Xiayun H, Tingting X, Xiaoshen W, Jing Y, Suqin W, et al: Treatment results of nasopharyngeal carcinoma: A retrospective analysis of 1837 cases in a single institute. Chin J Radiat Oncol 17: 335-339, 2008

20. Chinese clinical staging committee of nasopharyngeal carcinoma: Nasopharyngeal carcinoma' 92 staging modification work report. Chin J Radiat Oncol 18: 2-6, 2009.

21. 2010 consensus guidelines for intensity-modulated radiation therapy target area and dose design for the treatment of nasopharyngeal carcinoma. Chin J Radiat Oncol 20: 267-269, 2011

22. Lee N, Zhang Q, Kim J, Garden AS, Mechalakos J, Hu K, Le Q, Glisson BS, Chan AT and Pfister DG: Phase II study of concurrent and adjuvant chemotherapy with intensity modulated radiation therapy (IMRT) or three-dimensional conformal radiotherapy (3D-CRT) + Bevacizumab (BV) for locally or regionally advanced nasopharyngeal cancer (NPC) [RTOG 0615]: Preliminary toxicity report. Int J Radiat Oncol Biol Phys 78 (Suppl): S103-S104, 2010.

23. Gu X: Tumor radiation therapy. Beijing: Peking Union Medical College Press. 443-448, 2008

24. Wang XS, Yan C, Hu CS, Ying HM, He XY, Zhou ZR and Ding JH: Study of the medial group retropharyngeal node metastasis from nasopharyngeal carcinoma based on 3100 newly diagnosed cases. Oral Oncol 50: 1109-1113, 2014.

25. Ho FC, Tham IW, Earnest A, Lee KM and Lu JJ: Patterns of regional lymph node metastasis of nasopharyngeal carcinoma: A meta-analysis of clinical evidence. BMC Cancer 12: 98, 2012.

26. Wang XS, Hu CS, Ying HM, Zhou ZR, Ding JH and Feng Y: Patterns of retropharyngeal node metastasis in nasopharyngeal carcinoma. Int J Radiat Oncol Biol Phys 73: 194-201, 2009.

27. King AD, Ahuja AT, Leung SF, Lam WW, Teo P, Chan YL and Metreweli C: Neck node metastases from nasopharyngeal carcinoma: MR imaging of patterns of disease. Head Neck 22 275-281, 2000

28. Wang X, Li L, Hu C, Zhou Z, Ying H, Ding J and Feng Y: Patterns of level II node metastasis in nasopharyngeal carcinoma. Radiother Oncol 89: 28-32, 2008.

29. Ng SH, Chang JT, Chan SC, Ko SF, Wang HM, Liao CT Chang YC and Yen TC: Nodal metastases of nasopharyngeal carcinoma: Pattern of disease on MRI and FDG PET. Eur J Nucl Med Mol Imaging 31: 1073-1080, 2004.

30. Liu LZ, Zhang GY, Xie CM, Liu XW, Cui CY and Li L: Magnetic resonance imaging of retropharyngeal lymph node metastasis in nasopharyngeal carcinoma: Patterns of spread. Int J Radiat Oncol Biol Phys 66: 721-730, 2006.

31. Lv J, Wang R, Qing Y, Du Q and Zhang T: Magnetic resonance imaging analysis of regional lymph node metastasis in 1298 cases of nasopharyngeal carcinoma. Lin Chung Er Bi Yan Hou Tou Jing Wai Ke Za Zhi 26: 769-772, 2012 (In Chinese).

32. Edge SB, Byrd DR, Compton CC, Fritz AG, Greene FL and Trotti A: American joint committee on cancer staging manual. 7th ed. New York: Springer, 2009.

33. Tang LL, Guo R, Zhou G, Sun Y, Liu LZ, Lin AH, Mai H, Shao J, $\mathrm{Li} \mathrm{L}$ and Ma J: Prognostic value and staging classification of retropharyngeal lymph node metastasis in nasopharyngeal carcinoma patients treated with intensity-modulated radiotherapy. PLoS One 9: e108375, 2014.

34. Mao YP, Liang SB, Liu LZ, Chen Y, Sun Y, Tang LL, Tian L, Lin AH, Liu MZ, Li L and Ma J: The N staging system in nasopharyngeal carcinoma with radiation therapy oncology group guidelines for lymph node levels based on magnetic resonance imaging. Clin Cancer Res 14: 7497-7503, 2008.

35. Leslie S, Mary G and Chreitiann W: International union against cancer TNM Classification of Malignant Tumours. 7th ed, 2009.
36. Yue D, Xu YF, Zhang F, Lin L, Mao YP, Li WF, Chen L, Sun Y, Liu LZ, Lin AH, et al: Is replacement of the supraclavicular fossa with the lower level classification based on magnetic resonance imaging beneficial in nasopharyngeal carcinoma? Radiother Oncol 113: 108-114, 2014.

37. Li WF, Sun Y, Mao YP, Chen L, Chen YY, Chen M, Liu LZ, Lin AH, Li L and Ma J: Proposed lymph node staging system using the International Consensus Guidelines for lymph node levels is predictive for nasopharyngeal carcinoma patients from endemic areas treated with intensity modulated radiation therapy. Int J Radiat Oncol Biol Phys 86: 249-256, 2013.

38. Wakisaka M, Mori H, Fuwa N and Matsumoto A: MR analysis of Nasopharyngeal Carcinoma: Correlation of the pattern of tumour extent at the primary site with the distribution of metastasized cervically lymph nodes. Preliminay results. Eur Radiol 10: 970-977, 2000

39. Wang XS, Hu CS, Wu YR, Qiu XX and Feng Y: Analysis of computed tomography-based distribution of metastatic cervical nodes in 218 cases of nasopharyngeal carcinoma. Ai Zheng 23: 1056-1059, 2004 (In Chinese).

40. Teo P, Shiu W, Leung SF and Lee WY: Prognostic factors in nasopharyngeal carcinoma investigated by computer tomography-an analysis of 659 patients. Radiother Oncol 23: 79-93, 1992.

41. Heng DM, Wee J, Fong KW, Lian LG, Sethi VK, Chua ET, Yang TL, Khoo Tan HS, Lee KS, Lee KM, et al: Prognostic factors in 677 patients in Singapore with nondisseminated nasopharyngeal carcinoma. Cancer 86: 1912-1920, 1999.

42. Liu MZ, Tang LL, Zong JF, Huang Y, Sun Y, Mao YP, Liu LZ, Lin AH and Ma J: Evaluation of sixth edition of AJCC staging system for nasopharyngeal carcinoma and proposed improvement. Int J Radiat Oncol Biol Phys 70: 1115-1123, 2008.

43. Chen L, Mao YP, Xie FY, Liu LZ, Sun Y, Tian L, Tang LL, Lin AH, Li L and Ma J: The seventh edition of the UICC/AJCC staging system for nasopharyngeal carcinoma is prognostically useful for patients treated with intensity-modulated radiotherapy from an endemic area in China. Radiother Oncol 104: 331-337, 2012.

44. Pow EH, Kwong DL, McMillan AS, Wong MC, Sham JS, Leung LH and Leung WK: Xerostomia and quality of life after intensity-modulated radiotherapy vs. conventional radiotherapy for early stage nasopharyngeal carcinoma: Initial report on a randomized controlled clinical trial. Int J Radiat Oncol Biol Phys 66: 981-991, 2006.

45. Peng G, Wang T, Yang KY, Zhang S, Zhang T, Li Q, Han J and $\mathrm{Wu} \mathrm{G}$ : A prospective, randomized study comparing outcomes and toxicities of intensity-modulated radiotherapy vs. conventional two-dimensional radiotherapy for the treatment of nasopharyngeal carcinoma. Radiother Oncol 104: 286-293, 2012.

46. Lai SZ, Li WF, Chen L, Luo W, Chen YY, Liu LZ, Sun Y, Lin AH, Liu MZ and Ma J: How does intensity-modulated radiotherapy versus conventional two-dimensional radiotherapy influence the treatment results in nasopharyngeal carcinoma patients? Int $\mathrm{J}$ Radiat Oncol Biol Phys 80: 661-668, 2011.

47. Lee AWM, Ng WT, Chan LK, Chan OSH, Hung WM, Chan CC, Cheng PTC, Sze H, Lam TS and Yau TK: The strength/weakness ofthe AJCC/UICC staging system (7th edition) for nasopharyngeal cancer and suggestions for future improvement. Oral Oncol 48: 1007-1113, 2012

48. Zong J, Lin S, Lin J, Tang L, Chen B, Zhang M, Zhang Y, Xu L, Chen Y, Xiao Y, et al: Impact of intensity-modulated radiotherapy on nasopharyngeal carcinoma: Validation of the 7th edition AJCC staging system. Oral Oncol 51: 254-259, 2015.

This work is licensed under a Creative Commons Attribution-NonCommercial-NoDerivatives 4.0 International (CC BY-NC-ND 4.0) License. 